\title{
Teaching Diversity to Bilingual Children: Mexican-origin Kindergarteners' Discussions about Children's Literature Depicting Non-traditional Gender Roles
}

\author{
So Jung Kim, Josephia Tinajero \\ Department of Teacher Education, The University of Texas, USA
}

Copyright $(2016$ by authors, all rights reserved. Authors agree that this article remains permanently open access under the terms of the Creative Commons Attribution License 4.0 International License

\begin{abstract}
Despite the significant role of children's literature, little attention has been paid to how picture books depicting non-traditional gender roles can be incorporated in bilingual kindergarten classrooms as a medium to open discussions about gender roles. As part of a large-scale research project on multicultural education, this study investigated literary discussions about picture books depicting non-traditional gender roles to help young bilinguals challenge gender ideologies and gender stereotypes. Implementing a qualitative case study approach, the study focused on 16 five-year-old children of Mexican-origin at a charter school located in Texas. Findings suggest that the use of gender-themed picture books in a bilingual classroom can offer young bilingual children a multitude of opportunities to challenge dominant gender ideologies and develop critical perspectives on gender roles.
\end{abstract}

Keywords Gender Roles, Stereotypes, Children's Literature, Mexican-origin Children

\section{Introduction}

Children begin to develop gender identities and gender meanings in their early years [1-4]. Numerous studies over the last few decades have documented that children construct their gender schema at an early age and tend to categorize people on the basis of gender [5-6]. For instance, Zosuls et al. [7] argue that children identify with a social category as young as 27-30 months or even younger. They start to understand gender as a basic component of self, and develop gendered self and gender-typed roles in their daily interactions with their community members [8]. In this process, they sometimes develop biased attitudes toward male and female roles. Stereotyped gender roles are taught in numerous ways through media, songs, movies, children's books, and the popular culture [1, 9-10]. In particular, children's literature is an important cultural mechanism for teaching gender biases to children [11].

\section{Gender Representations in Children's Literature}

A growing number of researchers have paid attention to how gender stereotypes are represented in children's literature, as the influence of gender stereotypes on the development of gender identity in young children has been acknowledged by many studies done prior to it [12-14], [e.g. 11, 15-21]. These professionals have pointed out that, children's literature in the last decade has shown some improvement in reducing gender biases, yet subtle stereotypes still exist. Females are frequently depicted in the titles, pictures, and stories as figures who play passive roles, such as doing housework or other service-oriented tasks, whereas males are often shown as strong, brave, and emotionally non-expressive [17, 22-23]. Ruterana [24] pointed out that the way in which gender is represented in children's books shapes children's attitudes and perceptions of gender-appropriate behavior. Because stereotyped portrayals of gender can limit children's potential growth and affect their identity and self-esteem, it is crucial to help young children develop a stereotype-free understanding of gender roles from an early age. The issue of gender is especially important in Mexican/Mexican-American contexts when considering the patriarchal structure of the Hispanic culture [25].

\section{“Machismo and Familismo": Gender in Mexican Contexts}

Prior studies addressing the issue of gender roles of the Mexican American family point out the strong influence of machismo and familismo on Mexican-American families [26]. Historically, male and female roles in Mexican families had been represented differently [27]. Machismo reflects the dominance of men over women, and familismo, defined as a strong commitment toward the family, mirrors the importance of family as the primary unit within Mexican culture [28]. The cultural effect of machismo and familismo as principal elements within family roles have resulted in differences as to behavioral expectations in the roles of women and men in Mexican families [27]. First, men's roles were often characterized as patriarchal authority. Since the 
Mexican machismo culture places a high value on "manliness," as in many other patriarchal societies, men in the traditional Mexican families are "the boss and the head of the family" who make important decisions [28]. While men are expected to protect the honor and welfare of the family, Mexican women often take on the day-to-day responsibilities of raising the children [27, 29]. Mexican men and women become less tied to traditional gender role characteristics as gender roles have shifted over time [30]. However, extensive qualitative data still show that restrictive gender roles for men and women are heavily ingrained within the fabric of Mexican culture, and thus subtle gender ideology exists in a Mexican American society [31].

\section{Gender and Bilingual Children: Review of Prior Studies}

While the issue of gender in young children has been largely investigated in the past few decades [4, 12-14, 32], the studies examining gender-related issues in a bilingual/bi-literacy context are still very few. In terms of studies that explored the intersections of gender and bilingualism in literacy classrooms, most of the previous studies focused on gendered interactions, gender ideology, and gender acquisition/ negotiation in bilingual contexts such as the role of gender on social interactions in the classrooms [33] and how gender shapes bilingual children's literacy activities [34]. Other studies have investigated gender marking and agreement in Spanish-English bilingual children [35], the acquisition of grammatical gender in Dutch [36], and the impact of gender and bilingualism on cognitive development [37]. Review of the literature on gender in bilingual contexts demonstrates that there is very little available research on young bilingual children's discussions about traditional/non-traditional gender roles or their responses to picture books that challenge traditional gender roles. Our position is that early childhood/bilingual teachers and literacy educators should not ignore this issue because gender stereotypes can negatively influence not only children's gender identity and gender behavior, but also their academic performance and self-esteem [1, 38-39].

The current study aims to address the gap in research literature by investigating the possibilities of multicultural children's literature with non-traditional gender roles in bilingual classrooms as a medium to help young bilingual children develop critical attitudes toward gender roles. The study focused on 16 five-year-old children of Mexican-origin at a charter school located in Texas. This study focused on the following two research questions:

- What are children's responses within their social contexts to children's literature depicting non-traditional gender roles?

- How do literary discussions about traditional/non-traditional gender roles help young bilingual children challenge traditional gender roles and develop critical attitudes toward gender/gender roles?

Since there has been a continuous debate regarding the terminology used to describe multicultural literature, the study defines multicultural children's literature in a broad sense as books that incorporate "nationality, ethnicity, class, gender, religion, disability, age, sexual orientation and any other possible differences from the mainstream culture" [40: p.7]. Building upon the research that connects gender and literacy, the study approaches gender as being embedded in our social structure, and it affects literacy practices in early childhood classrooms [41]. In defining gender, the study adopted the notion that gender is not a fixed category but a complex set of situated relationships, and it is the range of social and relational characteristics that describe how individuals identify themselves by interacting with the world [3, 42-44]. Reader response criticism and sociocultural perspectives also informed an analysis of the ways the children responded to literature within social contexts and their negotiation on contradictory gender ideologies. The goal of the study is to further existing literature regarding gender and reading practices, multicultural children's literature, and early bilingual instruction. The fundamental goal of the study was to provide insights into how teachers can create supportive literacy environments in which bilingual children can develop a critical understanding of gender/gender roles from an early age.

\section{Methods}

The study was conducted at a PK through $7^{\text {th }}$ grade charter school located in Texas where $81 \%$ of the people were Hispanic and $73 \%$ of the population spoke Spanish. The student body consisted of $98 \%$ Hispanic, out of which $88 \%$ were of a low socioeconomic status. With the goal of helping the students develop the ability to communicate in both English and Spanish, the school featured a dual-language program, in which all of the teachers were bilingual.

This study focused on 16 kindergarten children (an equal balance of males and females) during read-aloud sessions in Ms. Valerie's classroom (note: all names are pseudonyms). Approximately $75 \%$ of the students were either Spanish speakers or Spanish-English bilinguals, and all of them had a Mexican origin. $80 \%$ were from low socioeconomic backgrounds, and 37\% were from single-parent homes. Ms. Valerie, a kindergarten teacher, had received a master's degree at a nearby university, and had worked at the school for two years. Her classroom was taken into consideration in this study because she read multicultural books, including books that challenged traditional gender roles. Also, with her strong belief in the importance of social interaction in learning, she allowed her students to share their responses and views during the literacy activities.

During a read-aloud session, Ms. Valerie read the literature in a whole group setting and talked about it in English and Spanish. She read a total of fifteen multicultural books during the observation period, which she selected in collaboration with the researchers. Of these books, the study focused on the following four since they dealt with non-traditional male and female roles. These books helped elicit lively conversations about gender, including gender stereotypes and different gender roles. 
Table 1. Selected Literature

\begin{tabular}{|l|l|l|}
\hline \multicolumn{1}{|c|}{ Title of Book } & \multicolumn{1}{|c|}{ Author } & \multicolumn{1}{c|}{ Story } \\
\hline Amazing Grace (1991) & Mary Hoffman & $\begin{array}{l}\text { Grace wants to play Peter Pan in her school play. She overcomes } \\
\text { the peers' doubts and fulfills her desire to perform Peter Pan. }\end{array}$ \\
\hline $\begin{array}{l}\text { What Mommies Do Best/What } \\
\text { Daddies Do Best (1998) }\end{array}$ & Laura Numeroff & $\begin{array}{l}\text { The first half shows mommies engaging in everyday activities } \\
\text { with their children. When flipping the book, it says that daddies } \\
\text { can do the same thing. }\end{array}$ \\
\hline I Want to Be a Cowgirl (2004) & Geanne Willis & $\begin{array}{l}\text { A young girl does not want to be a girl who cleans and cooks, or } \\
\text { be schoolgirl or a girlie girl. She has her heart set on becoming a } \\
\text { cowgirl. }\end{array}$ \\
\hline The Boy With Pink Hair (2011) & Perez Hilton & $\begin{array}{l}\text { A kindergartener, miraculously born with pink hair, learns how to } \\
\text { overcome teasing by focusing on his talent—cooking delectable } \\
\text { pink foods. }\end{array}$ \\
\hline
\end{tabular}

\section{Data Collection and Analysis}

The study adopted a qualitative approach to analyze the complexity of children's social interactions in a dual language context and the dynamics of the children's discussions about multicultural books depicting non-traditional gender roles. According to Dyson and Genishi [45], the purpose of qualitative studies is to arrive at a comprehensive and detailed understanding of phenomena by intensively analyzing an individual unit in relation to its context. The case study approach empowered the researchers to capture the details of the participating children's social interactions and to understand the complexities of the gender-related discussions in bilingual surroundings.

Multiple methods were utilized for data collection, including classroom observations, interviews with the parents and the teacher, parental surveys, and student artifacts. The process of the data collection was in accordance with the ethical standards of the responsible committee on human experimentation and with the Helsinki Declaration of 1975. The two researchers and graduate students visited Ms. Valerie's classroom twice a week over a five-month period, collecting the data and taking comparative field notes on the participants' experiences in the classroom. The field notes included commentaries, assumptions, questions, reactions, initial interpretations, and descriptions of activities. Classroom conversations were recorded with digital video/audio recorders [approximately 710 minutes in total], focusing on the children's responses to the literature, what language they used, how they interacted with each other, and what kind of literacy activities they were engaging in.

In addition, interviews were conducted with the parents and the teacher based on the technique of Seidman's model [46] of phenomenological interviewing. Interviews with the parents were conducted at the beginning of the study for 20 minutes to gain an in-depth understanding of the parents' gender attitudes, preferences in cross-gender play, and experiences in reading gender-themed books at home. The teacher was interviewed twice, for 30 minutes each time, to understand her teaching experiences, views toward gender roles, and goals in reading literature with non-traditional gender roles. Whenever the need arose, some informal interviews were conducted with the children. In order to get succinct and systematic data, a parental survey was conducted at the end of the program. Eighteen survey questions were developed by the two researchers, covering the parents' views toward books that challenged traditional gender roles, and if they had read gender-themed books to their child. Written texts were collected from the children during the observation period to see how they interpreted and recreated their readings through writing activities.

In order to analyze the verbal communication among the participants, the researchers transcribed the data as exactly as possible. When necessary, the researchers added interpretations of the conversations in notes under the text. The researchers also placed nonverbal information in parentheses before the dialogue. After the researchers grouped the data according to each literacy activity, some of the events were selected based on the previously mentioned research questions. Then, Emerson, Fretz, and Shaw's [47] preliminary coding method was employed for the initial analysis. The researchers conducted line-by-line and whole-document analyses, and categorized the data based on themes such as traditional gender roles, non-traditional gender roles, resistance, and culture. The researchers also adopted Sipe's [48] five categories of reader responses-analytical, intertextual, personal, transparent, and performative - when analyzing the children's literary responses. To verify the data, the triangulation technique recommended by Patton [49] of "comparing and cross-checking the consistency of information derived at different times and by different means within qualitative methods" was employed [p.559]. Also, using a member-check method [50], the researchers shared their analyses with other professionals to avoid any possible misunderstandings and increase the credibility of the data analysis.

\section{Findings}

The current study investigated the intersection between discussions about gender and multicultural children's literature in a dual language context. The participating 
children had a valuable opportunity to speculate about and reduce their own stereotypes toward gender and gender roles through reading the books that challenge traditional gender roles. Yet, at the beginning of the semester, some children often revealed unfavorable feelings toward characters playing nontraditional gender roles, which could be related to the discrepancy between the gender roles represented in books and their own gender role expectations.

\section{Children's Biases on Gender Roles}

Beach [51] argues that readers establish membership in a social community and learn the particular ways of roles unique to their communities. As members of their interpretive communities, the children seemed to have certain gender role expectations. Their biased attitudes toward gender roles should be understood within a larger gender discourse of the community, since "readers' responses inevitably reflect their beliefs and attitudes regarding power and privilege of the community" [52: p.72]. The children's stereotypical attitudes to gender roles were particularly salient when they discussed the domestic roles of females while reading the book What Mommies Do Best! What Daddies Do Best! [53]. The story presents scenes where animal mommies help their child ride a bike, make a snowman, bake a birthday cake, grow a garden, or give them a piggyback ride, etc. When the book is flipped, it says that daddies can do exactly the same thing. Before reading it, Ms. Valerie and the children had a conversation about gender roles as follows:

Teacher: So what should girls do?

Emma: Just paint their nails?

Teacher: Just paint their nails. What else? What about climbing trees? Is that supposed to be a girl's thing or no?

Children: No!
Emma: Just for the boy.

Teacher: Just for the boy? Then, what about—let me see- eating vegetables. Is it for girls or boys?

Hugo: (With a quiet voice) Niños! [Boys].

Sara: Niñas [Girls]

Pablo: Boys and girls!!

Teacher: What about working at home. Helping your mom. Doing your chores. Who can do that?

Children: (With a loud voice) Girls!!

Hugo: I just — my mom let me play and [she] just clean.

Teacher: What about your daddy?

Hugo: (Shaking his head negatively) No.

When the teacher asked the children some questions regarding different gender roles, they revealed gender stereotyping of both male and female roles, particularly the female ones. For instance, Emma considered that girls' roles would be "painting their nails," whereas climbing trees would be boys' roles. Also, most of the children, including Hugo, felt that "cleaning the house" would be a girls' role. Hugo, a boy who often exhibited stereotypical attitudes toward gender roles, indicated that both his father and he rarely did housework. In order to understand the children's responses to gender roles, it is important to consider their parents perceptions to gender roles because literary responses are constituted within social and cultural surroundings [52]. In the parent survey, $38 \%$ of the mothers indicated that they were stay-at-home mothers, and all of them answered that they were usually the ones who took care of the household chores. In terms of their own gender attitudes, more than $80 \%$ of the parents indicated they felt more comfortable with traditional gender roles. The following figure exhibits the participating parents' perceptions of gender roles.

\section{What are your perceptions concerning different gender roles?}

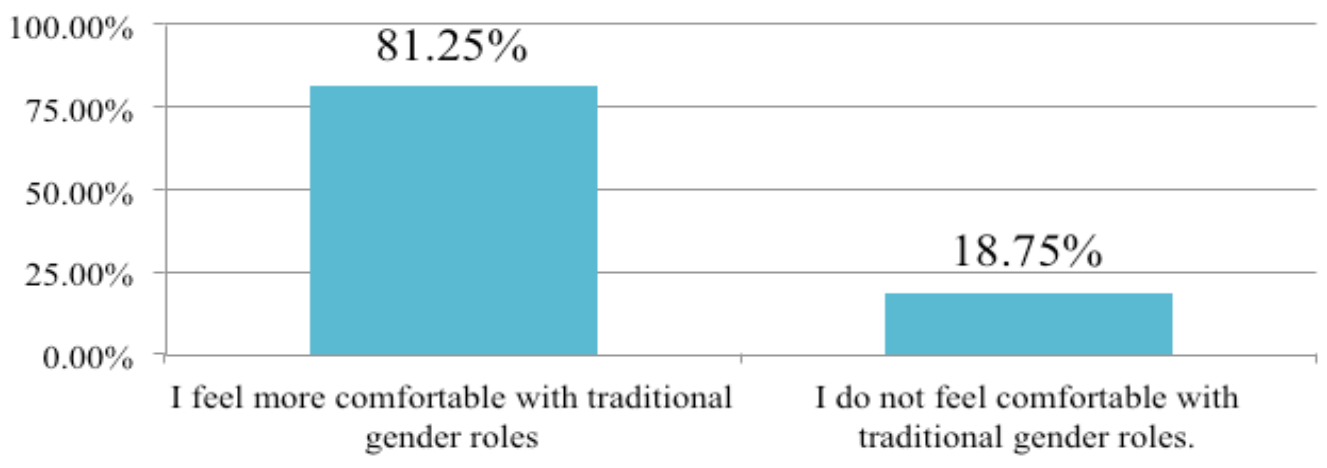

Figure 1. Parents' perceptions toward gender roles

In both the survey and interviews, most of the parents preferred non-traditional gender roles. Also, the children's limited exposure to reading books depicting non-traditional gender roles both at home and school could have affected their biased responses to male and female roles. In the figure below, approximately $70 \%$ of the parents indicated they had never (or rarely) read their child books depicting non-traditional gender roles. 


\title{
What are your experiences reading gender books to your child (or children) at home?
}

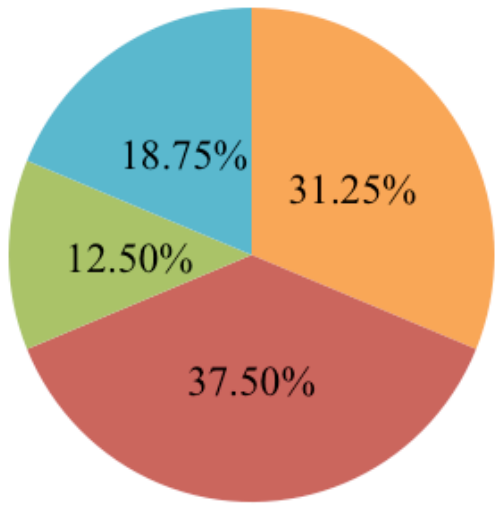

\author{
I have never read books that deal \\ with gender themes to my child. \\ - I rarely read gender-themed books \\ to my child (less than 5 times a \\ year). \\ I sometimes read gender-themed \\ books to my child (more than 2 \\ times a month). \\ I frequently read gender-themed \\ books to my child (more than 8 \\ times a month).
}

Figure 2. Parents' experiences of reading gender books to their child

Responses to in-depth interviews by the parents indicated that they had had no (or very limited) chance to read multicultural literature depicting non-traditional gender roles at home due to the children's young age and the lack of appropriate resources at home. Given this situation, when they read books that had main characters playing nontraditional gender roles, some of the children exhibited not only a bias toward gender roles but also had uncomfortable feelings toward them.

\section{Challenging Gender Stereotypes: Rethinking Male Roles}

Although the children demonstrated gender prejudices to the picture book characters at the beginning of the semester, their biased attitudes started to decrease as they discussed books challenging the traditional gender roles. As the teacher created comfortable and safe literacy surroundings where the children were encouraged to share their different ideas, the children were able to deepen their thoughts on different gender roles and speculate about their own gender stereotypes. Through bilingual literary discussions, the children could also learn that it is important to treat all people with respect regardless of gender and physical differences. For instance, reading The Boy with Pink Hair [54] presented the children with the story of a boy who was born with pink hair, and literary discussions about the book helped the children understand the value of being different:

Teacher: (Reading) One boy with shocking bright, beautiful pink hair made the world a little happier and a little pinker. And that's great thing (pointing at the illustration). Look at him. He looks so happy!

Emma: Contento [Happy].

Teacher: He followed his own special dream, and now he is just happy to be just who he is.

Margo: (Pointing at the illustration) Ellos están comiendo torta rosada! [They are eating pink cake] Teacher: Sí! [Yes] They are eating pink cake! All food on the table is pink. Look at this! He cooked all of these. [Do you] remember how sad he was at the beginning?

Norma: Sí! [Yes]

Teacher: Right. He was sad because he was different from his peers, but now (reading) his difference did make a difference.

Traditionally, cooking is considered as one of the duties of a woman. Yet, while reading the story of the boy with pink hair and discussing in both Spanish and English how he found his happiness through cooking, the children were able to think about what it meant to be different, and how they should approach differences around them. The conversation about differences also helped them acknowledge the importance of valuing all kinds of diversity in gender, skin color, physical abilities, and language, and to be proud of their different family traditions. Moreover, this opportunity helped them develop their literacy skills and practice vocabularies. Below is a sample of the children's writing (Note: Texts clarifying the writing were provided by the teacher.) 


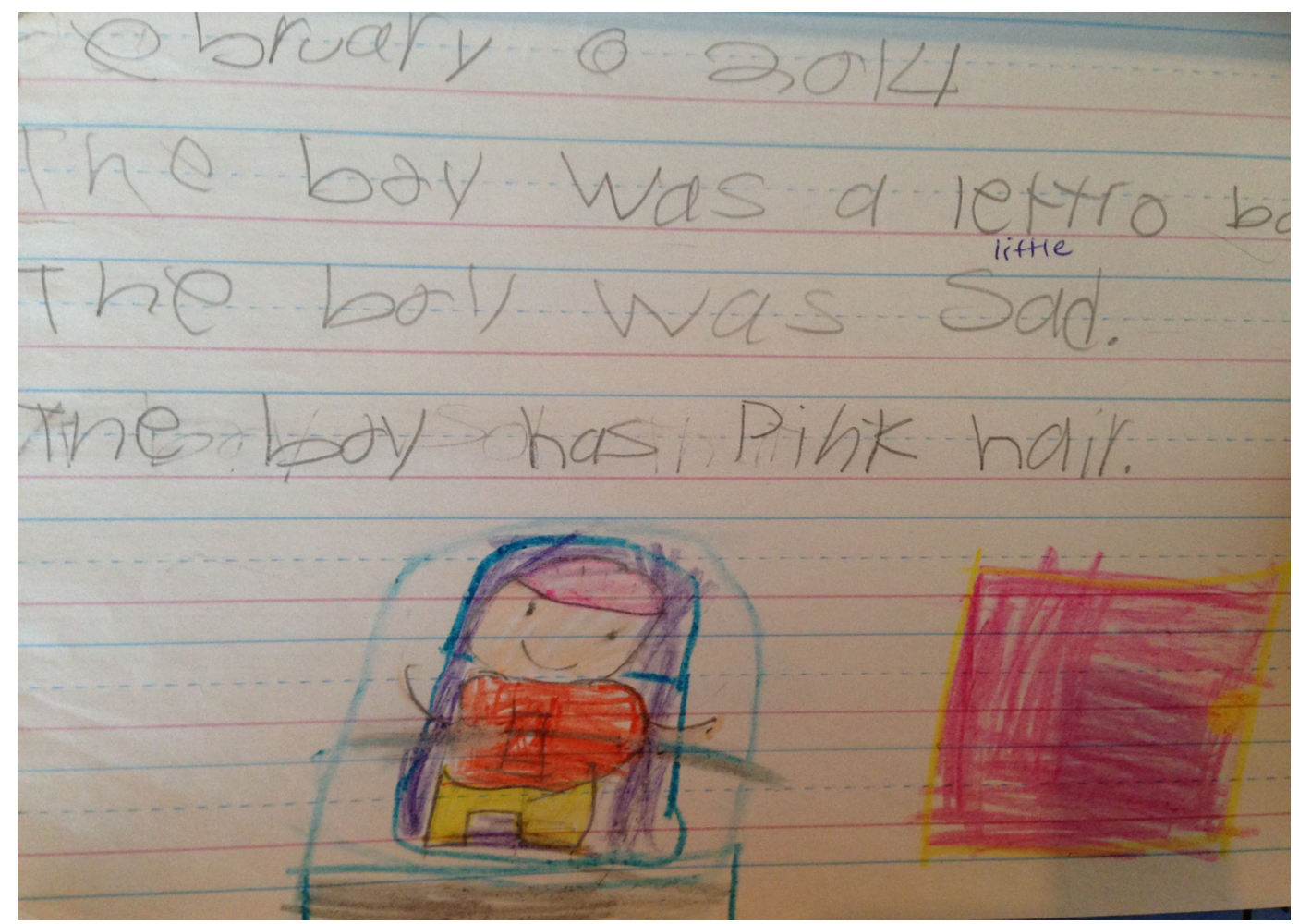

Figure 3. Emma's written text

In her written text, Emma wrote, "the boy was a little boy", "the boy was sad", and "the boy has pink hair." Through writing these sentences, she was able to review the story, and practice some vocabulary words such as boy and pink.

\section{Reconsidering Traditional Female Roles}

The picture books depicting non-traditional gender roles also served as a medium to help the children challenge dominant gender ideologies and rethink stereotypically female/male roles. The children's critical discussion about gender ideology was observed when they read the book $I$ Want to Be a Cowgirl [55], a story of a girl relating to her daddy that she wanted to be a cowgirl:

Teacher: (Reading) I've got my shiny spurs and boots. I've got my cowgirl hat. I'm leaving for the wild wild west. Now what's so wrong with that (pointing to the illustration)? Look at her hat. It looks great!

Sara: Puedo ver? [Can I see?]

Teacher: (Showing the illustration to Sara) So, what is she gonna do with the hat?

Gabriel: (Murmuring) She is going on the-

Emilio: wild West!

Sara: Texas. She is going Texas.

David: (Pointing to the illustration) This is Texas!

Teacher: Yes. She wanted to go to the wild West because she wanted to be-

Monique: A cowgirl!

Teacher: Yes. She wanted to be a cowgirl, not a girlie girl, doing cleaning and cooking at home. So, do you think it is a bad dream?

Sara: No.

Teacher: Right. It is not a bad dream and her dream is just a little bit different. You can be a girly girl or a wild girl, and you can do whatever you want to do.

While reading the girl's dream about hearing the eagles cry and watching the wolf cubs play, the teacher attempted to initiate gender-related discussions and facilitating critical thinking about female roles in young children. Through having conversations about the book such as "What is wrong with girls wanting to be a cowgirl?" "Is it just for boys?" and "Do all girls have to be a girly girl?," the children were able to evaluate and respond outside their box of perceptions as to cultural notions of gender, which helped them understand that people have different dreams and "it is ok to be different." Also, the discussions challenged their thoughts or beliefs about gender stereotypes such as "girls should not be rowdy" and "girls should be nurturing and polite, rather than adventuresome and independent."

\section{Exploring Gender Equality}

The literary discussions about gender helped the children learn not only non-traditional gender roles but also gender equality, which was exemplified in the book Amazing Grace [56]. It told about a girl who overcame her peers' doubts and fulfilled her desire to perform Peter Pan in the school play. While reading the book, the children discussed why Grace was not allowed to play Peter Pan, and how she would feel about her classmates' comments. As they finished the book, they had a conversation about gender equality, which is 
shared below:

Teacher: Can you tell me what happened in the story?

Emma: The girl wanted to be Peter Pan, but the boy said no.

Teacher: Why?

Emilio: Porque él es un niño! [Because he is a boy]. Teacher: Because Peter Pan was a boy.

Hugo: Because she was a girl.

Teacher: Right! So, is that fair?

Children: No!

Teacher: No. Then, are girls free to do whatever they want?

Children: Yes!!

Teacher: What about a police officer? Do you think girls can do it?

Children: Yes!

Teacher: Right. Girls can do whatever they want. Girls can be a police officer, a firefighter, a scientist - or president!! Boys also can do whatever they want too. They can be a cook and a nurse. Some men cook better than women!

As the children had conversations about the books, they learned that it was not positive behavior to treat people differently based on race or gender, and everyone deserved to be treated with respect regardless of gender. The conversations also encouraged them to explore non-traditional female occupations. Occupation is the major signal of self-identity, and girls as young as four have already internalized biased attitudes toward female occupations [57]. Through literary discussions about nontraditional female/male occupations, the children could challenge biases toward male/female occupations, and learn that females can do stereotypically male jobs and vice versa. The teacher also pointed out the benefits of reading those books as follows:

Teacher: Overall, by the end of the program, most children were more, like, open to gender and gender roles. At the beginning, they were like, "Princesses are for girls and monster trucks are for boys." But they started to be more open. Or they, at least I think, they understood that there are "differences," and they shouldn't judge or they shouldn't be like, "You cannot do this."

The teacher indicated that, although the degree of change in individual students varied, in general most of the children seemed to become more open to non-traditional gender roles through reading and discussing children's books depicting non- traditional gender roles.

\section{Discussion}

In this study, picture books depicting non-traditional gender roles and various book-related activities served as a tool to help the children explore the underlying gender ideologies and rethink gender roles. Children's literature is not simply an aesthetic literary work but "a literary vehicle in understanding the historical, political, spiritual, and sociological experiences" [58; p.141]. As the children were exposed to the books that portrayed non-traditional gender roles, they could confront gender biases and learn about human equality regardless of gender. The use of gender-themed picture books also offered them a multitude of opportunities to become familiar with non-traditional gender roles, to consider different perspectives, and to develop their literacy skills. The findings of this study enhanced the view that children's literature helps young children develop their understanding of complex social issues along with developing literacy skills [59]. The study also suggested the possibility of using picture books with non-traditional gender roles as a tool to help preschool and kindergarten-aged children challenge and question dominant gender ideologies and participate in gender-related discussions.

The study also supported the reader response view that readers' literary responses inevitably reflect the beliefs and attitudes regarding power and privilege in their communities [51-52]. In the survey and interviews with the parents, most of the parents indicated that they felt more comfortable with traditional gender roles, and rarely (or never) read books depicting non-traditional gender roles to their children. As the children had limited experiences in talking about gender or traditional/non-traditional gender roles at home, they displayed uncomfortable feelings toward characters playing non-traditional gender roles at the beginning of the semester. This finding enhanced the view that reading is a social and cultural act, instead of a solitary activity. Yet, it also suggested that children's literary responses to gender roles are constituted by "social, rhetorical, and cultural conventions" of the specific interpretive community [60: p.465].

In addition, the way in which the children switched their languages to share their responses, views, and ideas about gender roles suggested the potential of bilingual literary discussions to explore diverse gender-related issues. In this study, the teacher allowed the children to use both languages during literary discussions, which enabled them to share their ideas about gender roles in a more comfortable atmosphere. This finding suggested the possibility of bilingual literary discussions as a tool not only to facilitate literary understandings and reading comprehension [61-62], but also to help young bilinguals develop gender-related concepts and challenge dominant gender ideologies.

\section{Limitations and Future Direction}

The analyses of the gender discussions presented in this study provide evidence that challenges the common belief that Pre-K children are too young to discuss gender/gender roles. Since no studies have documented gender-related 
literary discussions with kindergarten or bilingual children, this study may open doors for future research about the role of literary discussions about gender in kindergarten and bilingual settings. The findings of this study may also provide teachers and educators with some insights on how interactive literature environments can help children challenge the dominant gender discourses and develop critical perspectives on gender roles. However, there is also a limitation in this study. Although the focal children likely represent emergent Spanish bilinguals from similar economic and cultural backgrounds, this study may not be representative of children from other racial, ethnic, or socioeconomic backgrounds. In this study, most of the children were from low socioeconomic backgrounds. Because the findings in this study were specific to the particular case, further research is needed for different ethnic and socioeconomic settings in order to deepen our understanding of bilingual kindergarten children's perceptions of gender/gender roles.

\section{Implications for Early Childhood Teachers}

The analysis of these discussions suggested several practical implications for early childhood and bilingual teachers. First, the study suggested that teachers should review the extent to which children's books perpetuate gender stereotypes. Children's literature has complex connections to differential relations of power within the political context, presenting "a microcosm of ideas, beliefs, from the dominant culture, including gender ideologies and scripts" [11: p.301]. Thus, teachers need to encourage children to question gender ideologies in children's books and help them co-construct new knowledge and understanding of gender roles. Teachers also should be careful with their own gender stereotypes because their ideology surrounding gender roles can directly contribute to children's adoption of gender stereotypes [8].

In addition, it is important that teachers not ignore how kindergarten children construct their own perspectives on gender roles. People generally behave in accordance with culturally defined gender roles [63]. Gender not only influences how children interact with each other, but also influences literacy practices and self-esteem [24]. In order to create a more supportive literacy environment, teachers should help them question their biases and acquire a stereotype-free understanding of gender/gender roles. Literature instruction also should provide children with the opportunity to examine gender norms and normative gender assumptions.

For bilingual teachers, it is important to pay attention to how bilingual students experience gender/gender roles at home, and how they interpret their gender experiences in their bilingual and bicultural surroundings. Darder [64] argued that being bilingual is more than speaking two languages because it is closely related to "bicultural identity" with different social norms, expectations, and worldviews [p.324]. Because bicultural literary experiences can influence gender-related activities at home in numerous ways, teachers should be aware of their young bilinguals' home culture [65-66] and allow them to "shuttle" between languages [67] during reading activities. Garcia and Wei [68] argued that young bilingual and multilingual children often code-switch, drawing on and intermingling linguistic features from different languages to achieve different communicative aims. Therefore, teachers should help them incorporate their rich and varied communicative repertoire into their reading practices by allowing them to use two [or more] languages.

The meanings of gender/gender roles are not fixed but learned through everyday life of children [69]. Thus, teachers should pay careful attention to how young bilingual children perceive gender roles in contemporary society, and help them grow as individuals with a critical understanding of gender/gender roles. This is important because young children's future can be enriched only when their teachers create an environment in which all children, irrespective of gender, can explore their capabilities as learners to their full potential.

\section{REFERENCES}

[1] Aina O, Cameron PA. Why does gender matter? Counteracting stereotypes with young children. Dimensions of Early Childhood. 2011; 39(3): 12- 20.

[2] Bennet M, Sani F, Hopkins N, Agostini L, Mallucchi L. Children's gender categorization: An investigation of automatic processing. British Journal of Developmental Psychology. 2000; 18: 97-102.

[3] Meyer EJ. Gender and sexual diversity in schools. New York, NY: Springer; 2010.

[4] Ruble D, Martin C. Gender development. In: Damon W (ed.) The handbook of child phycology. New York, NY: Wiley; 1998. P. 933- 1017.

[5] Mansson A. Becoming a preschool child: Subjectification in toddlers during their introduction to preschool, from a gender perspective. International Journal of Early Childhood. 2011; 43: 7-22

[6] Tamis-LeMonda CS, Shannon JD, Cabrera NJ, Lamb ME. Fathers and mothers at play with their 2- and 3-year-olds: Contributions to language and cognitive development. Child Development. 2004; 75: 1806- 1820.

[7] Zosuls M, Ruble N, Tamis-LeMonda S, Shrout E, Bornstein $\mathrm{H}$, Greulich K. The acquisition of gender labels in infancy: Implications for sex-typed play. Developmental Psychology. 2009; 45: 688-701.

[8] Blaise M. Playing it straight: Uncovering gender discourses in the early childhood classroom. New York, NY: Routledge; 2005 .

[9] Bigler R. The role of classification skill in moderating environmental influences on children's gender stereotyping: A study of the functional use of gender in the classroom. Child Development. 1995; 66: 1072-1087. 
[10] Landt SM. Books for boys: Multicultural literature with strong male characters. International Journal of Multicultural Literature. 2013; 15(1). Available from http://ijme-journal.or g/index.php/ijme/article/viewFile/531/pdf.

[11] Taylor F. Content analysis and gender stereotypes in children's books. Teaching Sociology. 2003; 31: 300-311.

[12] Adebowale SA, Yusuf OB, Palmuleni EA. Child's gender preference: What is the regional situation among women in Nigeria? Gender \& Behaviour. 2014; 12(3): 5868-5884.

[13] Fabes RA, Martin CL, Hanish LD. Young children's play qualities in same-, other-, and mixed-sex peer groups. Child Development. 2003; 74: 921-932.

[14] Halim ML, Ruble D, Tamis-LeMonda C, Shrout PE. Rigidity in gender-typed behaviors in early childhood: A longitudinal study of ethnic minority children. Child Development. 2013; 84(4): 1269-1284.

[15] Corner. What are examples of books for young children that break gender stereotypes? Anti-defamation league. 2013. Available from:

http://www.adl.org/assets/pdf/education-outreach/What-areExamples-of-Books-Gender-Stereotypes.pdf

[16] Gooden AM, Gooden MA. Gender representation in notable children's picture books: 1995-1999. Sex Roles. 2001; 45 89-101.

[17] Lee J. Gender representation in Hong Kong primary school ELT textbooks - A comparative study. Gender and Education. 2014; 26(4): 356-376.

[18] Morgan H. Gender, racial, and ethnic misrepresentation in children's books: A comparative Look. Childhood Education. 2009; 85(3): 187.

[19] Narahara MM. Gender stereotypes in children's picture books. 1998. Retrieved from http://files.eric.ed.gov/fulltext/ ED419248.pdf

[20] Ryan CL, Patraw JM, Bednar M. Discussing princess boys and pregnant men: Teaching about gender diversity and transgender experiences within an elementary school curriculum. Journal of LGBT Youth. 2013; 10: 83-105.

[21] Varga-Dobai K. Gender issues in multicultural children's literature - Black and third-world feminist critiques of appropriation, essentialism, and us/other binary oppositions. Multicultural Perspectives. 2013; 15(3): 141-147.

[22] Mattix A, Sobolak MJ. The gender journey in picture books: A look back to move forward. Childhood Education. 2014; 90(3): 229-233.

[23] Trepanier-Street ML, Romatowski JA. The influence of children's literature on gender role perceptions: A reexamination. Early Childhood Education Journal. 1999; 26(3): $155-159$.

[24] Ruterana PC. Children's reflections on gender equality in fairy tales: A Rwanda case study. The Journal of Pan African Studies. 2012; 4(9): 85-101.

[25] Kulis S, Marsiglia F, Nagoshi J. Gender roles, externalizing behaviors, and substance use among Mexican-American adolescents. Journal of Social Work. 2010; 10(3): 283-307.

[26] Tamez EG. Familism, machismo and child rearing practices among Mexican Americans. Journal of Psychosocial Nursing and Mental Health Services. 1981; 19(9): 21-25.

[27] Galanti GA. The Hispanic family and male-female relations: Overview. Journal of Transcultural nursing. 2003; 14(3): 180-185.

[28] Toro-Morn MI. Familismo. In: Loue S, Sajatovic M (eds.) Encyclopedia of Immigrant Health. New York, NY: Springer; 2015. p. 672-274.

[29] Hirsch J. A Courtship before marriage. Los Angeles, CA: University of California Press. 2003.

[30] Gutmann MC. The meanings of macho: Being a man in Mexico City. Los Angeles, CA: University of California Press. 1996.

[31] Williams N. The Mexican American family: Tradition and change. Lanham, MD: Rowman \& Littefield. 1990.

[32] Serbin LA, Moller LC, Gulko J, Powlishta KK, Colburne KA. The emergence of gender segregation in toddler playgrounds. In: Leaper C. (ed.) Childhood gender segregation. San Francisco, CA: Jossey-Bass. 1994. p. 7-17.

[33] Heller M. Gender and public space in a bilingual school. In: Pavlenko A, Blackledge A, Piller I, Teutsch-Dwyer M. (eds.) Multilingualism, second language learning and gender. Berlin: Mouton de Gruyter. 2001. p. 257-282.

[34] Orellana MF. Literacy as a gendered social practice in two bilingual classrooms. Paper presented at the Annual Meeting of the American Educational Research Association, New Orleans: LA. 1994.

[35] Montrul S. The role of experience in the acquisition and production of diminutives and gender in Spanish: Evidence from L2 learners and heritage speakers. Second Language Research. 2013; 29(1): 87-118.

[36] Unsworth S. Age and input in the acquisition of grammatical gender in Dutch. Second Language Research. 2008; 24(3): 365-395.

[37] Ryskin RA, Bwon-Scgnudt S. The impact of gender and bilingualism on cognition: the case of spatial perspective-taking. 2011 Retrieved from http://projects.ict.us c.edu/nld/semdial2011/proceedings/semdial2011_ryskin.pdf

[38] Allen A, Allen D, Sigler G. (). Changes in sex role stereotyping in Caldecott Medal Award picture books 1938-1988. Journal of Research in Childhood Education. 1993; 1: 67-13.

[39] Kamler B. Constructing gender and difference: Critical research perspectives in early childhood. Creskill, NY: Hampton; 1999.

[40] Cai M. Multicultural literature for children and young adults: Reflections on critical issues. Westport, CT: Greenwood; 2002.

[41] Ramsey PG. Teaching and learning in a diverse world. New York, NY: Teachers College; 1998.

[42] Klein AM. Little big men: Bodybuilding subculture and gender construction. Albany, NY: State University of New York; 1993.

[43] Weiler K. Feminist engagements: Reading, resisting, and 
revisioning male theorists in education and cultural studies. New York, NY: Routledge; 2001. p. 67-87.

[44] Wright JA. Feminist poststructuralist methodology for the study of gender construction in physical education: Description of a study. Journal of Teaching in Physical Education. 1995; 15(1): 1-24

[45] Dyson AH, Genishi C. On the case. New York, NY: Teachers College; 2005.

[46] Seidman I. Interviewing as qualitative research: A guide for researchers in education and the social sciences. New York, NY: Teachers College; 1991.

[47] Emerson R, Fretz R. Shaw L. Writing ethnographic fieldnotes. Chicago, IL: University of Chicago; 1996.

[48] Sipe LR. Storytime: Young children's literary understanding in the classroom. NY: Teachers College; 2008.

[49] Patton MQ. Qualitative research and evaluation methods (3rd ed.). Newbury Park, CA: Sage Publications; 2002.

[50] Kirk J, Miller ML. Reliability and validity in qualitative research. Beverly Hills, CA: Sage; 1986.

[51] Beach R. New direction in research on response to literature. In: Farrell EJ, Squire JR. (eds.) Transactions with literature: A fifty-year perspective. Urbana, IL: National Council of Teachers of English; 1990. p. 65-77.

[52] Beach R. Students' resistance to engagement with multicultural literature. In: Rogers E, Soter AO. (eds.) Reading across cultures: Teaching literature in a diverse society. New York, NY: Teachers' College; 1997. p. 69-94.

[53] Numeroff L. What mommies do best/What daddies do best. New York, NY: Simon \& Schuster Books for Young Readers; 1998.

[54] Hilton P. The boy with pink hair. New York, NY: Celebra Children's Books; 2011.

[55] Willis J. I want to be a cowgirl. New York, NY: Henry Holt and Company; 2004.

[56] Hoffman M. Amazing Grace. New York, NY: Dial Books; 1991.

[57] Care E, Deans J, Brown R. The realism and sex type of fourto five-year-old children's occupational aspirations. Journal of Early Childhood Research. 2007; 5(2): 155-168.
[58] Brooks W, McNair JC. "But this story of mine is not unique": A review of research on African American children's literature. Review of Educational Research. 2009; 79(1): 125-162.

[59] Moller KJ, Allen J. Connecting, resisting, and searching for safe places: Students respond to Mildred Taylor's "The Friendship." Journal of Language Literacy. 2000; 32(2): 145-186.

[60] Beach R, Hynds S. Response to literature. In: Barr R, Kamil ML, Mosenthall P, Pearson PD. (eds.) Handbook of reading research. New York: Longman; 1991. p. 253-289.

[61] Martínez-Roldán CM， López-Robertson JM. Initiating literature circles in a first-grade bilingual classroom. The Reading Teacher. 1999 ; 52: 270-281.

[62] Martínez-Roldán CM, Sayer P. Reading through linguistic borderlands: Latino students' transactions with narrative texts. Journal of Early Childhood Literacy. 2006; 6: 293-322.

[63] Raffaelli M, Onatai LL. Gender socialization in Latino/a families: Results from two retrospective studies. Sex Roles. 2004; 50: 287-299.

[64] Darder A. Buscando America: The contributions of critical Latino educators to the academic development and empowerment of Latino students in the U.S. In: Sleeter CE, McLaren PL. (eds.) Multicultural education, critical pedagogy, and politics of difference. New York, NY: State University of New York Press; 1995. p. 310-318.

[65] Cummins J. Negotiating identities: Education for empowerment in a diverse society. Ontario, CA: California Association for Bilingual Education; 1996.

[66] Shin SJ. Developing in two languages: Korean children in America. Clevedon, UK: Multilingual Matters; 2005.

[67] Garcia O. Education, multilingualism and translanguaging in the 21 st century. In: Skutnabb-Kangas T, Phillipson R, Mohanty AK, Panda M. (eds.) Social justice through multilingual education. New York, NY: Multilingual Matters; 2009. p. 140-158.

[68] Garcia O, Wei L. Translanguaging language, bilingualism and education. New York, NY: Palgrave Macmillan; 2013.

[69] Bhana D, Nzimakwe T, Nzimakwe P. Gender in the early years: Boys and girls in an African working class primary school. International Journal of Educational Development. 2011; 31: 443-448. 